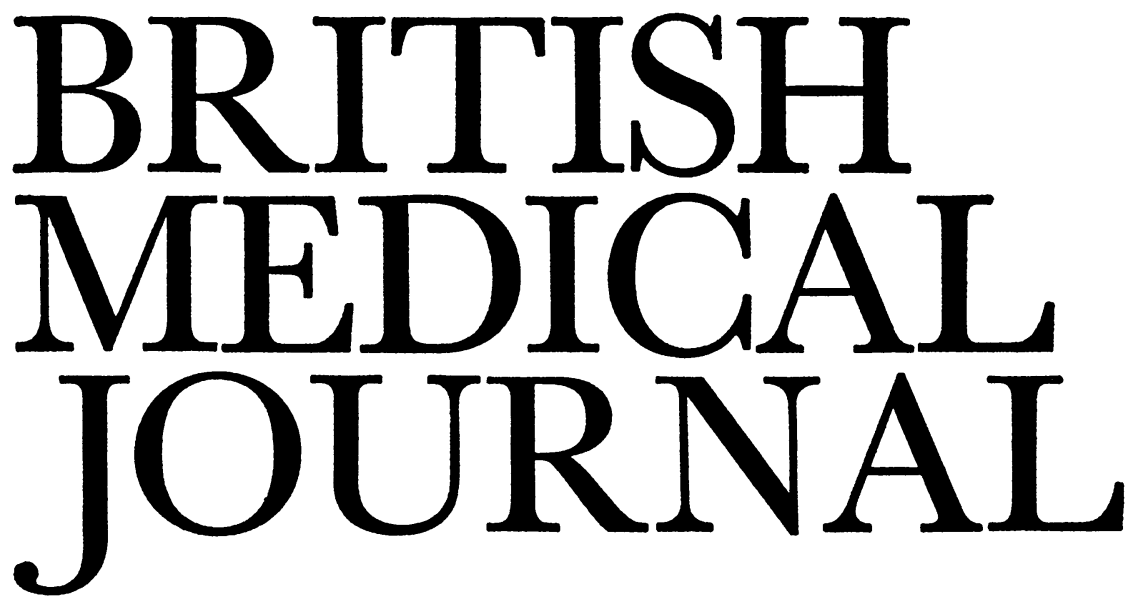

LONDON SATURDAY 11 AUGUST 1973

\title{
Does Methaqualone Cause Neuropathy?
}

Some concern has been expressed about the addictive effects of methaqualone and of its combination with diphenhydramine (Mandrax). ${ }^{1}$ But other serious side effects apart from idiosyncratic skin sensitivity have received little attention. It is therefore worrying that a recent German report ${ }^{2}$ describes peripheral neuropathy after the regular use of methaqualone by itself or in combination with diazepam, meprobamate, or promazine.

J. Finke and U. Spiegelberg describe the cases of seven adults (four men, three women) whose ages ranged from 30 to 74 and who attended neurological and psychiatric clinics in Stuttgart. All were said to have developed numbness and tingling after taking methaqualone in doses of $200 \mathrm{mg}$ to 600 $\mathrm{mg}$ at night for periods ranging from two months to two years. In the case of the patient who had been taking this night sedation for only two months the dose is not stated. Complaints of persistent numbness and tingling in the limbs and extremities, with distal muscle wasting and weakness, foot-drop, depressed tendon reflexes, and impairment of the sensations of touch, vibration, and joint position provided the clinical evidence for a diagnosis of peripheral neuropathy.

In two patients superficial nerves were tender. In three of the four patients on whom electromyographic studies were done evidence of peripheral neuropathy is reported to have been found but the actual findings are not described. None of the patients had a muscle or nerve biopsy, but the cerebrospinal fluid protein was slightly raised in three out of four, a finding compatible with a peripheral neuropathy. Though serum levels of vitamin $B_{12}$ were not measured, deficiency is unlikely to have been of much importance, because Schilling tests for gastrointestinal absorption of $B_{12}$ were normal in four patients and doubtfully abnormal in one. Two of the patients were prediabetic, including an elderly woman who developed tingling after five weeks' administration of $1-1 \frac{1}{2}$ tablets daily containing methaqualone $250 \mathrm{mg}$ and promazine $25 \mathrm{mg}$. One was suspected of alcoholism. Nerve conduction tests are not reported.

Even though most of the patients described probably did suffer from a peripheral neuropathy, the evidence for both the site of the lesion and the aetiological role of methaqualone is inconclusive. But if methaqualone was responsible it is surprising that there have been no other reports in the ten years that have passed since its introduction. Moreover, it is unfortunate that the authors do not indicate if the patients improved on stopping ingestion of the drug.
Nevertheless, this report needs careful consideration. There has been some interest previously in the possible occurrence of peripheral neuropathic changes, because patients shortly after taking the drug sometimes experience transient acroparaesthesiae as an immediate prelude to deep sleep (first reported ten years ago in the correspondence columns of the $B . M . F^{3}$ ), but animal studies were reported to show neither a neuropathic nor a teratogenic effect. ${ }^{4}$ While such dysaesthesiae are more likely to arise centrally than peripherally, their relative frequency, together with a suggestion of infrequent chronic peripheral symptoms, do merit careful reappraisal. A double-blind but very limited study has not disclosed any evidence of peripheral neuropathy, ${ }^{5}$ but in an earlier study ${ }^{6}$ from Stuttgart, in which 232 patients taking methaqualone were examined, 44 had electromyographic tests performed on them and one was found to have a "chronic polyneuropathy of unknown aetiology." In this case methaqualone was not thought to have contributed to it because the patient had taken only 17 tablets of $200 \mathrm{mg}$ each. The discrepancy between these studies and that of Finke and Spiegelberg $^{2}$ might be the result of differences in selection of patients, and it raises the possibility of an idiosyncratic response as in the case of thalidomide neuropathy.

In Great Britain it might be advisable if patients taking methaqualone were now examined by their general practitioners and any suspicion of foot-drop, sensory disturbance, or depression of tendon reflexes were reported to the Committee on Safety of Medicines.

1 Matthew, H., British Medical fournal, 1973, 3, 174

2 Finke, J., and Spiegelberg, U., Nervenarzt, 1973, 44, 104.

3 McQuaker, W., and Bruggen, P British Medical fournal, 1963, 1, 749.

4 Buckler, J. W., Hall, J. E., and Morton, E. V. B., British Medical fournal, 1963, 1, W49.,

5 Volk, W., Medizinische Welt, 1972, 23, 388.

6 Kunze, K., Noelle, H., and Prüll, G., Arzneimittel-Forschung, 1967, 17 1052 .

\section{Freedom in Hospital}

No matter how egalitarian a society may claim to be, a hierarchy of privilege is never hard to discover in it. Where Great Britain is fortunate is in the number of watchdog organizations we have whose self-appointed task is to see 
that people are not too grievously exploited in one way or another by those higher up the scale. An excellent example of this sort is the National Association for Mental Health. For many years it has snapped at the ankles of the Establishment in defence of one particularly inarticulate and powerless minority, the mentally disordered.

From time to time the N.A.M.H. has published reports subtly entitled Mind. The tenth in the series ${ }^{1}$ was recently issued with the subtitle "Patients' Rights: the Mentally Disordered in Hospital." It is mainly concerned with the deprivations that patients admitted to psychiatric hospitals suffer as the result of the exercise of compulsory orders, the most important being the loss of liberty. Though compulsion is always to be regretted, it is at times necessary in the interests of the patient and of society at large. But it would not be too cynical to point out that, in contrast to the special hospitals, to abscond from most conventional mental hospitals presents no great difficulty. Indeed it is sometimes said that to abscond is far too easy and that it is just those patients who are most dangerous who may be the ones to go.

This illustrates the anomalous position in which mental hospitals have been thrust by virtue of the two incompatible roles, therapeutic and custodial, they are expected to fulfil as an unforeseen consequence of the Mental Health Act, 1959. And the custodial function is increasing in importance. This is reflected in the statistics given in the Mind report for compulsory admissions in the years 1962 and 1970. A comparison of these two years shows that the number of orders under Section 135-6 (Place of Safety Orders) have more than doubled-namely, from 740 to 1,493 . Furthermore, if it is assumed that "other admissions" refers to those under Part V of the Act (admission of patients concerned in criminal proceedings, etc). it is to be noted that here again the numbers have increased-namely, from 1,584 to 1,725 . This means that there has been a substantial increase in the number of mentally abnormal offenders compulsorily admitted, either without prosecution in the case of Sections $135-6$ or as a result of prosecution under Part $V$, for whom the medical profession is not initially responsible.

The report then explores the way in which patients may be subject to inadequate or unsatisfactory treatment or exploitation. It takes up the familiar theme of the scant attention paid to long-term patients by consultant psychiatrists. Unfortunately the case made out is all too convincing and confirms what has long been recognized-the inadequate medical staffing of our mental hospitals. Just as important is the right of patients to refuse treatment. The report stresses the failure of the 1959 Act to say anything about the treatment of people against their will. A demand is made that the Department of Health and Social Security should give firm guidance on the subject to the Responsible Medical Officers. It is only fair to comment that the Secretary of State, Sir Keith Joseph, in a written answer in the House of Commons on 23 January stated briefly but succinctly the position as he sees it. ${ }^{2}$ His reply was as follows: "I am advised that, in the case of a patient detained for treatment under the Mental Health Act, any recognized form of treatment which is considered necessary for such disorder may lawfully be administered without the consent of the parient. Where, however, the patient is capable of understanding what is proposed, it is the normal practice to explain this to him and, if possible, to obtain his agreement."

In an attempt to safeguard patients against exploitation the report discusses the danger of their use as "cheap labour" and the unfairness of not being paid the rate for the job. It emphasizes too the golden rule that in all forms of employment the therapeutic work programmes should be made for the patients rather than "patients being made to fit into an arbitrary programme of little relevance to their usual way of life." It deals next with the satisfaction of ordinary human needs, in particular adequate feeding and the right, when possible, of patients to wear their own clothes and to acquire possessions of their own. All in all it recommends measures to improve their way of life and advocates the means whereby they may retain their dignity. The danger to civil rights is stressed, in particular the disfranchisement of those patients in hospital for the mentally disordered who have no home address. Commenting on the review procedures for detained patients the report deplores the rubber-stamp method of extending compulsory orders by hospital management committees. And it asks for patients appealing to mental health review tribunals to be represented either by qualified lawyers or by a lay "patient's friend," for when this is done the number of recommendations for discharge is substantially increased.

The points discussed, though not necessarily new, are nevertheless of importance, and none of the recommendations made can be ignored. But perhaps the most important is contained in the final paragraph. This refers not to the sins of the hospitals themselves but to the lack of facilities in the community to support the patients after they leave. The last sentence should be pondered: "The right to leave means nothing if there is nowhere else to go."

\footnotetext{
1 Mind Report No. 10. National Association for Mental Health, 39 Queen

Anne Street, London W1M OAJ.
2 Hansard, 23 January 1973, col. 77.
}

\section{Clinical Diagnosis of Reye's Syndrome}

Reye's syndrome is characterized pathologically by cerobral oedema without cellular infiltration or demyelination, and fatty degeneration of the viscera, especially the liver. ${ }^{1}$ Its cause is unknown. Mortality in reported series varies from $25 \%$ to $80 \% .^{2-4}$ Recovery may be complete 4 or associated with serious neurological deficits. ${ }^{2}$ Whether the syndrome is a distinct entity has been questioned, but the clinical, biochemical, and pathological abnormalities in childhood ${ }^{14-7}$ are remarkably consistent.

The disorder occurs in children aged 2 months to 15 years. The typical case presents as an acute encephalopathy with seizures and disturbances of consciousness proceeding rapidly to deep coma. Sustained seizures, with periods of tonic posturing with flexed elbows, clenched fists, and extended legs and hyperpnoea or irregular respiration are symptoms that suggest the diagnosis. There are no focal neurological signs or meningismus. Mild to moderate hepatomegaly is the only clinical evidence of visceral disease, and even this is lacking in $50 \%$ of cases. Deepening coma with death in 24 to 48 hours is the usual course. Clinical diagnosis is based on these findings in the absence of other apparent causes of acute encephalopathy: Confirmation is obtained by finding at biopsy intense fatty infiltration of the liver, seen as diffuse vacuolation of the hepatocytes without nuclear displacement and no hepatocellular necrosis. ${ }^{7}$ The nucleoli may be enlarged and irregular. Elec- 